\title{
The Experience of Model Minority for High- and Low-Income Asian American Students
}

\author{
Amy Yun-Ping Chen ${ }^{a}$
}

\begin{abstract}
The author examines the differentiation of self-identity, school treatment, and academic struggle between two Asian American students in U.S. Midwest urban school environments. Using an interview study, the author focuses on understanding the students' perspectives in relation to the label of model minority. The purpose of the study is to investigate how social, academic, and economic factors affect these students, including different outcomes in terms of school achievement and self-identity formation. The findings aim to help urban educators approach complex factors regarding minority students' educational opportunities. Comprehensive results identified that: (1) The concept of model minority significantly affects Asian American students at all levels of daily life; (2) Urban schools continue reinforcing social reproduction and producing perceptions based on socioeconomic background and intersectional discrimination; (3) The evidence in the study shows that school environments do not aid students in valuing their cultural capital; (4) Students from different social classes present different linguistic and behavioral patterns; and (5) Social stratification significantly influences students' perspectives in response to the Asian stereotype, self-identity, and racial hierarchy in school and society.
\end{abstract}

\section{Keywords}

Cultural capital, racial hierarchy, model minority, self-identity, social reproduction

For many decades, Asian Americans have been perceived by the popular press and the media as the most successful minority group in the United States (Park and Lee 2010; Velasquez 2015; Zhang 2010). That is to say, there are many images of Asian Americans depicting as geeks, or hard workers as well as submission and compliance (Bittle 2013; Zhang 2003). These are all associated with the concept of model minority. The achievement of Asian Americans is typically measured in education, occupation, and income. However, the public usually ignores the economic and educational disparities between different opportunity levels that exist in the population (Bassett 2011; Brand 1987; Lowe 2015). The stereotypes also mask problems occurring in the lives of numerous Asian Americans (Park and Lee 2010;
Zhang 2010). Therefore, the misconception of the Asian American population becomes more complex.

Many Asian Americans adapt the myth of "model minority" in their daily lives in order to assimilate into the dominant culture and to be recognized. For instance, Asian American parents often hold high expectations and largely emphasize their children's educational and behavioral outcomes, which create the main aspiration for their children to attend college and accomplish success in the future (Lamborn, Nguyen, and Bocanegra 2013; Zakeri 2015). Chua (2011; 2014)

aSaint Louis University, USA

Correspondent Author:

Amy Yun-Ping Chen, $1 \mathrm{~N}$ Grand Blvd, St. Louis, MO, USA, 63103 
also indicated that a strict, no-excuses style of parenting is supposedly commonplace and traditional across all Asian and Asian American households. This shows a significant implication that explains the way Asians, especially Chinese parents, raise such stereotypically successful children in the United States. Furthermore, as Goodwin (2003: 16) described:

Parents apparently cannot help but continue to hold on to the illusion that their children can become what they are not: simultaneously fully assimilated and "Americanized", and fully Asian, not only with all culture intact, but with a disposition toward making deliberate choices that will ensure cultural maintenance.

Parental expectations and parent-child relationships result in more complex issues in relation to Asian American children's self-identity formation. Thus, the children usually struggle with the balance of two cultural realities, which also may cause some impacts on their academic performance (Goodwin 2003).

Regarding stereotypes in school environments, many Asian American students are viewed academically successful, and the model minority stereotype is frequently propagated by peers, administrators, teachers, and the public (Brand 1987; Lee 1994; Ng, Lee, and Pak 2007; Park and Lee 2010; Zakeri 2015). Indeed, students from different Asian ethnic groups reveal different academic aspirations and outcomes. The interplay of the model minority stereotype and the ethnic myth has a way of creating confusion and enhancing racial biases (Bassett 2011; Lew 2006; Lowe 2015; Park and Lee 2010; Tran and Birman 2010; Wing 2007). Moreover, students identified as Southeast Asian Americans are essentialized into the discourse of urban low-achieving, low-income, and culturally deficient minority students; in contrast, schools are likely to hold high expectations for Chinese, Korean, or Japanese American students and attribute their success to motivation and diligence (Chhuon and Hudley 2011; Lee 1994; 2001; 2005; Lowe 2015; Wing 2007).
Southeast Asian American students also are likely judged against the standards of white hegemonic masculinity; for instance, lack-confident discourses, swaggering gait, and subgroup cultural outfits are signs of deviance and masculinity as well as markers of violence (Lee 2001; 2005).

In addition, in the United States, there appears to be a fairly widespread view, both among many academics and the wider public that White Americans are at the top of a racial hierarchy (Hochschild and Weaver 2007; Song 2004). Also, Ogbu argued that differences in achievement levels between voluntary (Asian) and involuntary (Black or Latino) minorities are connected to their respective perceptions regarding future opportunities and their perceptions and responses to school and society. Voluntary minorities often pay little attention to prejudging discrimination from the dominant power (Lee 1994; Ogbu and Simons 1994). Further, identity refers to the patterns of meaning that review how individuals perceive a concept of self and recognize themselves in contrast to others through cultures and experiences (Salomone 2010). Erikson also articulated "Identity crisis appeared to grow out of the experience of emigration, immigration, and Americanization" (as cited in Salomone 2010: 69). Many minority students consider or internalize assimilation as a pathway to help them reach future success and social mobility, so they forge relationships with peers outside of their own ethnic group and resist their own racial heritage by identifying with the white society (Conchas 2001; Lee 1994; 2001; 2005; MacLeod 2009; O’Connor 1997; Zakeri 2015).

Today's U.S. education plays a key role in the reproduction of inequality (MacLeod 2009). Racial order and socioeconomic capital often matter in a number of ways such as educational access and school performance. The label of poorness or richness determines the quality of formal education the child receives. Class also significantly interplays with race (Byrne 2006; McCall 2001). The hierarchical structure 
insures people in the top position with a plethora of privilege and belittles the ones in the bottom (Byrne 2006; McCall 2001). As a result, such injustice deprives disadvantaged children's human rights, impedes their learning opportunities, and annihilates the concept of democratic education.

U.S. education has been devastating to educational attainment to disadvantaged groups and creates disparities between different populations. Children from different racial and social backgrounds present different cultural capital (Bourdieu 1977; Bourdieu and Passeron 1990; MacLeod 2009). Cultural capital, which is often associated with educational attainment, intellect, or style of speech, refers to non-economic assets that are passed from generation to generation (MacLeod 2009). The education system usually rewards the possession of cultural capital and supports the reproduction of inequality. The distribution of school knowledge and philosophy reinforces social stratification and encourages cultural and social reproduction (Anyon 1981; 2005; Greene and Anyon 2010; Zirkel et al. 2010). Therefore, Yosso (2005) suggested that teachers should use critical race theory to value students' community cultural wealth. According to Mari Matsuda (1991), critical race theory aims to "develop a jurisprudence that accounts for the role of racism in American law and that works toward the elimination of racism as part of a larger goal of eliminating all forms of subordination" (as cited in Yosso 2005: 71). More importantly, teachers have the responsibility to understand their students' cultures and explore students' past experiences in order to support each child in developing effective learning skills and reaching future life success (Bittle 2013; Conchas 2001; Moll et al. 1992; Murjani 2014; Yosso 2005).

\section{METHOD}

Semi-structured and in-person interviews were conducted with participants. The interviews were comprised of a set of open-ended questions and potential probes, along with some demographic questions. A series of pre-established questions was based on the work of earlier literature reviews and served as a primary guideline. The length of each interview was about 50 to 60 minutes. The two participants were second-generation Asian Americans. The high-income student was attending a private elite high school in a Midwest urban area where student populations were approximately $80 \%$ whites, $7 \%$ blacks, and $10 \%$ Asians. Nearly $90 \%$ of the teachers were whites, middle class, and monolingual English speaking. The low-income participant was studying in an urban public school. The school included $10 \%$ whites, $78 \%$ blacks, and $5 \%$ Asians; $80 \%$ of the teachers were whites and middle class; $15 \%$ of the teachers were blacks. During the interview sessions, both participants were two months from receiving their high school diplomas and facing the struggle of decision-making for future directions.

\section{DISCUSSIONS}

\section{Model Minority and Daily Life}

The concept of model minority significantly affected the Asian American students at all levels of daily life. During the interview conversations, both students described how their parents applied the model minority profile to direct their academic progress and influence their future choices. Their parents' expectations only concentrated on the successful entry to math, science, and medical fields. Both families displayed the combination of authoritarian and authoritative parenting styles. Moreover, the students articulated that they experienced the model minority stereotype in school environments every day. Peers and teachers closely scrutinized their learning achievement and placed high expectation standards to judge their performance. Such phenomena often restrict Asian American students' life exploration and 
produce psychological stress and pressure. For instance, the high-income student faced more stress about stereotypes from peers, but he usually received more recognition, privilege, and academic support from teachers as long as he played by the rules and met the public expectation. The image of Asians as America's model minority leads high-income or high-achieving students to become anxious about peer competition or to have some issues about mental wellbeing such as depression. In contrast, the low-income student articulated that people in his school often criticized the low-achieving and low-income Asian students as the shame of Asians and labeled them as useless and inferior. That image leaves those Asian American students who live below the poverty line and those who are low-achievers invisibly or labels them as disgraced figures. The students likely hold low self-esteem and exhibit violent behaviors. The findings are associated with the conclusion of Whaley and Noel (2013) that many researches have underestimated the mental health needs of Asian American students. There is the urgency to consider the effects of racial stereotypes on the students in order to prevent any risks. Also, there is a huge differentiation in terms of how people view the high- and low-income masculine and meek Asian American students. In the private elite school, masculine Asian American students were perceived as the ideal, or perfect figures, because of intellectual and manly features; meek students were seen as geeks. On the other hand, in the low-performance urban public school, masculine Asian American students were perceived as displaying violent, deviant, and criminal features; meek students were viewed as losers academically and socially.

\section{Model Minority and Social Reproduction}

There is a significant difference in the treatment that students received from different school structures. This may be relevant to the discussions that schools cater to different classes of students and emphasize different values based on predetermined roles (Anyon 1981; 2005; Greene and Anyon 2010; MacLeod 2009; Zirkel et al. 2010). In this study, the high-income student largely acquired assistance from teachers who considered Asian American students as honorary whites. Teachers assumed that these students were all hardworking, self-disciplined, and intellectual in this private elite school. Oftentimes, teachers recognized minority students' learning abilities and provided additional educational support to help them cope with academic difficulties. The student-teacher relationship was more interactive and positive. Contrarily, the low-income Asian American student was stereotyped as inferior and criminal similarly to the negative stereotypes for Black American students. In this low-performing public school, White American students still held more privileges. Teachers did not aid minority students in improving academically nor deal with behavioral issues. Teachers were also not aware of students' learning problems; instead, teachers used harsh language and judgments to criticize minority students and conducted discipline-based pedagogy.

Derived from the students' experiences, the evidence reveals that education in urban areas tends to reinforce social inequality rather than function as a social equalizer. School systems strongly foster the competitive success and advantage of the high-income population and encourage intersectional discrimination against low-income students. As a result, low-income, low-achieving, and minority students suffer more obstacles and struggle with more biases in school environments.

\section{Model Minority and Cultural Capital}

The research demonstrates that both schools do not support students in valuing their cultural capital such as home languages. The private elite school encourages minority students to accommodate the dominant culture and to confirm the reality of the model minority stereotype. The evidence can be seen 
in the research of Zhou and Bankston (1998) as well. In New Orleans, Vietnamese immigrant students who conformed to the norms of the community and model identity were rewarded with access to social capital. The public school uses the standards of white power to criticize minority students' behaviors. Many minorities encounter either resistance or assimilation to the mainstream order. Some students maintain their cultural identity and fight the power structures; others accept the essence of cultural stereotypes and work hard to receive approval from the mainstream power.

Frequently, the majority of minority youths feel trapped between two worlds. They struggle to form their own identities. Students usually have to choose between their traditional identities or to ignore the experiences of their early lives and to be Americanized. As seen in Waters' (1996) study, many Korean immigrant students choose to internalize racial hierarchy and seek to enact the model minority identity and desire status as honorary whites. Some may survive after the transition of identity formation and embrace their full cultural characteristics; contrarily, some may reject their identity, or establish negative perspectives against their own ethnicity (Lee 1994; 2005; O’Connor 1997). However, race, class, culture, and schooling are all intertwined in multicultural urban schools. It is certainly important that teachers can constitute funds of knowledge, which implies the knowledge students gain from their cultures and families, understand each student's cultural background, and use the information to facilitate minority students in academic achievement. With the aid of such knowledge, teachers can deliver the message of social awareness and cultural respect to every individual as well (Moll et al. 1992).

\section{Linguistic and Behavioral Cultural Capital}

Students from different social statuses present different linguistic and behavioral patterns, which are related to Bernstein and Heath's theory of the development of "elaborated and restricted codes", to the communication of meanings (MacLeod 2009: 17). During the interviews, the high-income Asian American student frequently used "I" as the beginning word in most of his sentences. The low-income Asian American student used "we" or "Asian Americans" when responding to the questions about the model minority stereotype. The evidence indicates that students from different social classes and school structures reveal distinct class-specific forms of communication.

The outcomes may be associated with their social and experiential practices from home and school. The high-income Asian American student attends a private elite school and accepts Americanization and conformity with whites. The current U.S. school system reinforces class hierarchy and provides access to elaborated codes to certain populations, which results in high-income students being gifted with advantages for the development of cultural capital which is associated with educational attainment (Anyon 1981; MacLeod 2009). Moreover, by adopting Americanized values and assimilated attitudes, these students have more opportunities to approach an individualist ideology and be more aware of their individual goals. According to the current findings and the theory of linguistic cultural capital, urban schools continue to focus on a powerful mechanism of social reproduction not only through the aspect of school knowledge, but also the level of self-identity and personal value.

\section{Social Stratification and Self-identity}

Social stratification significantly influences students' perspectives in response to the Asian stereotype, self-identity, and racial hierarchy in school and society. Although Ogbu's theory of voluntary and involuntary minorities explains the differentiation of achievement between Asian American students and Black American students, this interpretation may not hold for all Asian American groups (Ogbu and Simons 1994). In the study, socioeconomic backgrounds and 
the level of academic outcome are the main factors influencing the model minority stereotype and school experience. The findings are similar with Lee's (1994; 2005) studies. Due to high social status, adequate educational support, and honorary recognition, the high-income Asian American student was optimistic about his personal life chances. He internalized the stereotypical categorization and embraced the rules of social expectation and white standards. In contrast, the low-income Asian American student was more pessimistic and had negative viewpoints regarding public perceptions concerning Asians, and he used more aggressive and resistive behavior to respond to racist situations. $\mathrm{He}$ also assumed that all minority groups largely experienced intersectional discrimination. There are huge disparities in the life experience among Asian Americans, and the model minority profile continues affecting different aspects of ideology and response toward the Asian population in the United States, which not only involves racial contexts but also more importantly social, economic, and educational factors.

\section{CONCLUSIONS}

Overall, this study confirms many of the findings from past literature. The results also highlight how the lives and ideologies of Asian American students are continuously shifted by the model minority stereotype and the dominant culture, especially in relation to racial, social, economic, educational, and cultural aspects. In particular, there is a significant connection between a student's socioeconomic status and school experience, which directly and indirectly affects his attitudes and perspectives about self-identity and social order.

The sample in this research may reflect a disproportionate view of all Asian American students whose experiences possibly reveal varying reactions because of geographic differences, family traditions, and cross-cultural relationships. Future research should include diverse groups from the Asian population such as Korean, Indian, Cambodian, Filipino, and so forth. Every group has unique cultural, political, and social characteristics and practices. It is important to specify and investigate how the concept of model minority creates different outcomes for each group.

Moreover, the current approach did not involve responses from female students, so it is unknown whether they would express similar or distinct points of view. There also might be some variables in relation to students' personal traits and preferences, which could possibly create the impact on their personal, educational, and social experiences. Future studies should take a further intersectional approach to compare the distinctions between genders, personality traits, high- and low-achievers from different school structures and to examine how high- and low-income students display different or similar consequences regarding academic achievement and identity formation.

However, the evidence in this research suggests the importance of raising urban educators' awareness regarding stereotypes among minority populations and preventing prejudiced perspectives. Educators should be concerned about multiple in-depth investigations when looking at the cause and effect of urban or ethnic stereotypes. Such kinds of inquiries are not only relevant to racial and cultural factors but also, significantly, socioeconomic contexts and school structures.

\section{References}

Anyon, J. 1981. "Social Class and School Knowledge." Curriculum Inquiry 11(1):3-42.

- 2005. Radical Possibilities: Public Policy, Urban Education, and a New Social Movement. New York, NY: Routledge.

Bassett, P. F. 2011. “The Model Minority?" Independent School 70(2):9-12.

Bittle, A. 2013. "I Am Asian American. Uncover the True Diversity Beneath the Asian American Label." Teaching 
Tolerance 44:57-60.

Bourdieu, P. 1977. "Cultural Reproduction and Social Reproduction." Pp. 487-511 in Power and Ideology in Education, edited by J. Karabel and A. H. Halsey. New York, NY: Oxford University Press.

Bourdieu, P. and J. C. Passeron. 1990. Reproduction in Education, Society and Culture (Theory, Culture, \& Society). Thousand Oaks, CA: SAGE Publications Inc.

Brand, D. 1987. "The New Whiz Kids: Why Asian American Are Doing So Well, and What It Costs Them." Time 130(9):42-51.

Byrne, B. 2006. White Lives: The Interplay of "Race", Class and Gender in Everyday Life. New York, NY: Routledge.

Chhuon, V. and C. Hudley. 2011. "Ethnic and Panethnic Asian American Identities: Contradictory Perceptions of Cambodian Students in Urban Schools." The Urban Review 43:681-701.

Chua, A. 2011. Battle Hymn of the Tiger Mother. New York, NY: Penguin Books.

- 2014. The Triple Package: How Three Unlikely Traits Explain the Rise and Fall of Cultural Groups in America. New York, NY: Penguin Books.

Conchas, G. 2001. "Structuring Failure and Success: Understanding the Variability in Latino School Engagement." Harvard Educational Review 71(3):475-504.

Goodwin, A. L. 2003. "Growing up Asian in America. A Search for Self." Pp. 3-25 in Asian American Identities, Families, and Schooling, edited by C. C. Park, A. L. Goodwin, and S. J. Lee. Greenwich, CT: Information Age Publishing.

Greene, K. and J. Anyon. 2010. "Urban School Reform, Family Support, and Student Achievement." Reading \& Writing Quarterly: Overcoming Learning Difficulties 26(3):223-236.

Hochschild, J. and V. Weaver. 2007. "The Skin Color Paradox and the American Racial Order." Social Forces 86(2):643-670.

Lamborn, S. D., J. Nguyen, and J. O. Bocanegra. 2013. 'Hmong American Adolescents' Perceptions of Mothers' Parenting Practices: Support, Authority, and Intergenerational Agreement." Asian American Journal of Psychology 4(1):50-60.

Lee, S. J. 1994. "Behind the Model-Minority Stereotype: Voices of High- and Low-Achieving Asian American Students." Anthropology \& Education Quarterly 25(4):413-429.

_ 2001. "More Than 'Model Minorities' or 'Delinquents': A Look at Hmong American High School Students." Harvard Educational Review 71(3):505-528.

- 2005. Up Against Whiteness: Race, School, and Immigrant Youth. New York, NY: Teachers College Press,
Columbia University.

Lew, J. 2006. "Burden of Acting Neither White nor Black: Asian American Identities and Achievement in Urban Schools." The Urban Review 38(5):335-352.

Lowe, G. 2015. "The Model Minority Narrative and Its Effect on Asian American Identity and Social Status." Pp. 323-350 in Modern Societal Impacts of the Model Minority Stereotype, edited by N. D. Hartlep. Hershey, PA: Information Science Reference.

MacLeod, J. 2009. Ain't No Makin' It: Aspirations and Attainment in a Low-Income Neighborhood. Boulder, CO: Westview Press.

McCall, L. 2001. Complex Inequality: Gender, Class and Race in the New Economy. New York, NY: Routledge.

Moll, L. C., C. Amanti, D. Neff, and N. Gonzales. 1992. "Funds of Knowledge for Teaching: Using a Qualitative Approach to Connect Homes and Classrooms." Theory Into Practice 31(2):132-141.

Murjani, M. 2014. "Breaking Apart the Model Minority and Perpetual Foreigner Stereotypes: Asian Americans and Cultural Capital.” The Vermont Connection 35:78-90.

Ng, J., S. S. Lee, and Y. K. Pak. 2007. "Contesting the Model Minority and Perpetual Foreigner Stereotypes: A Critical Review of Literature on Asian Americans in Education." Review of Research in Education 31:95-130.

O'Connor, C. 1997. "Dispositions Toward (Collective) Struggle and Educational Resilience in the Inner City: A Case Analysis of Six African-American High School Students." American Educational Research Journal 34(4):593-629.

Ogbu, J. and H. D. Simons. 1994. Cultural Models of School Achievement: A Quantitative Test of Ogbu's Theory on Cultural Models of Literacy: A Comparative Study. Project 12. Berkeley, CA: National Center for the Study of Writing and Literacy.

Park, G. C. and S. J. Lee. 2010. "The Model Minority Stereotype and the Underachiever: Academic and Social Struggle of Underachieving Korean Immigrant High School Students." Pp. 13-28 in Beyond Stereotypes: Minority Children of Immigrants in Urban Schools, edited by R. Saran and R. Diaz. Rotterdam, the Netherlands: Sense Publishers.

Salomone, R. C. 2010. True American. Language, Identity, and the Education of Immigrant Children. Cambridge, MA: Harvard University Press.

Song, M. 2004. "Introduction: Who's at the Bottom? Examining Claims About Racial Hierarchy." Ethnic \& Racial Studies 27(6):859-877.

Tran, N. and D. Birman. 2010. "Questioning the Model Minority: Studies of Asian American Academic Performance." American Psychological Association 
1(2):106-118.

Velasquez, T. G. 2015. "From Model Minority to 'Angry Asian Man': Social Media, Racism, and Counter-Hegemonic Voice." Pp. 90-132 in Modern Societal Impacts of the Model Minority Stereotype, edited by N. D. Hartlep. Hershey, PA: Information Science Reference.

Waters, M. C. 1996. "Ethnic and Racial Identities of Second-Generation Black Immigrants in New York City." Pp. 171-197 in The New Second Generation, edited by A. Portes. New York, NY: Russell Sage Foundations.

Whaley, A. L. and L. T. Noel. 2013. "Academic Achievement and Behavioral Health Among Asian American and African American Adolescents: Testing the Model Identity and Inferior Minority Assumptions." Soc Psychol Educ 16:23-43.

Wing, J. Y. 2007. "Beyond Black and White: The Model Minority Myth and the Invisibility of Asian American Students." The Urban Review 39(4):455-487.

Yosso, T. J. 2005. "Whose Has Capital? A Critical Race Theory Discussion of Community Cultural Wealth." Race Ethnicity and Education 8(1):69-91.

Zakeri, B. H. 2015. "A Double-Edged Sword: Side Effects of the Model Minority Stereotype on Asian Immigrants in the U.S." Pp. 231-258 in Modern Societal Impacts of the Model Minority Stereotype, edited by N. D. Hartlep. Hershey, PA: Information Science Reference.
Zhang, Q. 2010. "Asian Americans Beyond the Model Minority Stereotype: The Nerdy and the Left out." Journal of International and Intercultural Communication 3(1):20-37.

Zhang, Y. 2003. "Immigrant Generational Differences in Academic Achievement: The Case Study of Asian American High School Students." Pp. 201-224 in Asian American Identities, Families, and Schooling, edited by C. C. Park, A. L. Goodwin, and S. J. Lee. Greenwich, CT: Information Age Publishing.

Zhou, M. and C. L. Bankston. 1998. Growing up American: How Vietnamese Children Adapt to Life in the United States. New York, NY: Russell Sage Foundation.

Zirkel, S., F. Bailey, S. Bathey, R. Hawley, U. Lewis, D. Long, ... A. Winful. 2010. "Isn't That What 'Those Kids' Need?' Urban Schools and the Master Narrative of the 'Tough, Urban Principal'." Race Ethnicity and Education 14(2):137-158.

\section{Bio}

Amy Yun-Ping Chen, Ph.D., Curriculum and Instruction, Saint Louis University, USA; research fields: multicultural education, teacher education, social justice education, immigrant education, and bilingual education. 